\title{
Experimental and Computational Study of
}

\section{Dopamine as an Electrochemical Probe of the}

\section{Surface Nanostructure of Graphitized N-doped}

\section{Carbon}

James A. Behan, ${ }^{a}$ Md. Khairul Hoque,${ }^{a}$ Serban N. Stamatin,${ }^{a, b}$ Tatiana S. Perova,${ }^{c}$ Laia VilellaArribas, ${ }^{a}$ Max Garcia-Melchor ${ }^{a^{*}}$ and Paula E. Colavita ${ }^{a^{*}}$

${ }^{a}$ School of Chemistry, CRANN and AMBER Research Centres, Trinity College Dublin, College Green, Dublin 2, Ireland.

${ }^{\mathrm{b}}$ University of Bucharest, Faculty of Physics, 3Nano-SAE Research Centre, 405 Atomistilor Str., Bucharest-Magurele 077125, Romania

${ }^{\mathrm{c}}$ Department of Electronic and Electrical Engineering, Trinity College Dublin, Dublin 2, Ireland and ITMO University, 49 Kronverskiy pr., Saint Petersburg, 197101, Russia. 


\section{Abstract}

$\mathrm{N}$-doped carbon nanomaterials have received increased attention from electrochemists due to their applications in the metal-free electrocatalysis of important redox processes. In this work, a series of graphitized undoped and nitrogen-doped carbon electrodes prepared by thermal annealing of sputtered amorphous carbon films were prepared and characterized using a combination of X-ray photoelectron spectroscopy and Raman spectroscopy. Adsorption of the surface-sensitive redox probe dopamine at each electrode surface was then studied using cyclic voltammetry and the results correlated to the physico-chemical characterisation. Results indicate that dopamine adsorption is influenced by both the nitrogen surface chemistry and the degree of graphitization of the carbon scaffold. N-doping, with predominantly graphitic-N sites, was found to increase adsorption of dopamine more than 6 fold on carbon surfaces when the introduction of $\mathrm{N}$ atoms did not result in substantial alterations to the $\mathrm{sp}^{2}$ network. However, when an identical type and level of $\mathrm{N}$-doping is accompanied by a significant increase in disorder in the carbon scaffold, adsorption is limited to levels comparable to those of nitrogen-free carbon. Density functional theory studies of dopamine adsorption on graphene and $\mathrm{N}$-doped graphene model surfaces showed that dopamine interacts via $\pi$-stacking at the graphene surface. The Gibbs free energy of adsorption on $\mathrm{N}$-doped graphenes were estimated at 12-13 $\mathrm{kcal} \mathrm{mol}^{-1}$, and found to be approximately twice that of undoped graphenes. Results suggest that chemical changes resulting from $\mathrm{N}$-doping enhance adsorption; however, high coverage values depend on the availability of sites for $\pi$-stacking. Therefore, the structurally disruptive effects of $\mathrm{N}$-incorporation can significantly depress the dopamine response by limiting the availability of basal sites, ultimately dominating the overall electrochemical response of the carbon electrode. 


\section{Introduction}

Nitrogenated carbon materials have received much attention in recent years, in large part due to the discovery of their activity in the metal-free electrocatalysis of important reactions including the oxygen reduction reaction $(\mathrm{ORR})^{1-2}$ and oxygen evolution reaction $(\mathrm{OER}) \mathrm{.}^{3-4}$ The synthesis of nitrogenated carbons is facile, versatile and can be carried out using low cost reactants, with nitrogen having been successfully incorporated into a variety of different nanocarbons including amorphous carbon, ${ }^{5-7}$ graphene, ${ }^{8-11}$ and carbon nanotubes. ${ }^{4,}{ }^{12}$ The literature has been reviewed recently. ${ }^{13-14}$

Most nitrogenation protocols result in different nitrogen sites incorporated into the material. Nitrogen may be substitutionally incorporated into the carbon scaffold as a so-called graphitic-N site, resulting in the N-doping of the carbon scaffold, or in other chemical forms such as pyridinic-N and pyrrolic-N, both of which are necessarily associated with the formation of vacancies and edge sites within the carbon matrix. ${ }^{15}$

The existence of different $\mathrm{N}$-sites poses a challenge to researchers carrying out structureactivity studies for electrocatalytic applications. A good example is the extensive work done on the ORR at nitrogenated carbon surfaces, which has focused on elucidating active sites for oxygen adsorption or attempting to correlate electrochemical activity to the presence of one or more N-moieties (most commonly pyridinic-N and graphitic-N) in the carbon matrix. ${ }^{6,16}$ By contrast, factors such as the degree of graphitization, the size and packing of graphitic clusters and the number of defect sites present at the surface have not been considered in great detail, which may be attributed to the lack of a convenient electrochemical means of probing carbon nanostructures. 
The electrochemistry of catechols such as dopamine (DA) is notable for its high degree of sensitivity to the surface chemistry of electrodes. The work by McCreery and co-workers ${ }^{17-18}$ on glassy carbon electrodes shows that catechol adsorption on electrode surfaces may have a dramatic effect on the charge transfer kinetics, due to the self-catalysis of one or more of the steps in the 'scheme of squares' mechanism often used to describe the 2-electron/2-proton process of catechol oxidation. ${ }^{19-20}$ Recently, catechol has been shown to adsorb on graphene nanoplatelets $^{21}$ and the adsorption of DA on graphene, in particular, has been investigated by means of theoretical calculations. ${ }^{22-23}$ Due to its biological relevance as an important neurotransmitter, DA has also been intensely studied in the context of electroanalysis and simultaneous detection in the presence of co-analytes such as ascorbic acid. ${ }^{24-26}$ DA also has relevance to the nitrogenated amorphous carbon literature in this context, ${ }^{26-28}$ because these carbons may be engineered to have low background currents and wide potential windows. ${ }^{29}$ Interestingly, despite intense focus on tailoring carbon electrode composition and preparation for electroanalytical determinations of DA, comparatively less work has been devoted to investigating the potential application of DA as a probe of surface nanostructuring for N-doped carbons.

In this work we prepared carbon model systems based on topographically smooth graphitized amorphous carbon with and without incorporated nitrogen, and characterized them using a combination of cyclic voltammetry, X-ray photoelectron spectroscopy (XPS) and Raman spectroscopy. We report what we believe to be the first use of DA as a probe for the surface structure of a disordered nitrogenated carbon material. Results indicate that DA adsorbs on both nitrogenated and nitrogen-free graphitized carbon surfaces, with both the surface chemistry and carbon nanostructure influencing the DA coverage. These results were corroborated by 
computational studies of DA adsorption on model graphitic clusters via density functional theory (DFT). Our results are expected to have relevance to both the electrochemical detection of DA at nitrogenated carbon surfaces, and the structure-activity characterization of carbon based materials for surface-catalysed processes such as the ORR.

\section{Experimental Methods}

Chemicals and Materials. Dopamine hydrochloride (98\%, Aldrich), Sulfuric Acid ( $\geq 95 \%$, Ultratrace) Hexane (analytical standard) and Methanol (semiconductor grade) were used without further purification.

Substrate Preparation. Glassy carbon (GC) disks (HTW Sigradur radius $0.25 \pm 0.05 \mathrm{~cm}$ ) were prepared by polishing with progressively finer grades of alumina slurry (Buehler), sonicating and rinsing with copious Millipore water as reported previously. ${ }^{4}$ Clean disks were either used immediately for electrochemical measurements or, in the case of amorphous carbon and nitrogenated amorphous carbon depositions, mounted in a custom-made Teflon holder and placed in the vacuum chamber for coating via magnetron sputtering prior to characterization, as previously described. ${ }^{5}$ In the case of substrates for Raman and XPS measurements, B-doped silicon wafers (MicroChemicals; resistivity 5-10 $\Omega-\mathrm{cm}$ ) were prepared via previously reported protocols. ${ }^{5}$

Preparation of Carbon Electrodes. Undoped and N-doped amorphous carbon thin film electrodes were prepared by magnetron sputtering followed by a thermal annealing treatment. Briefly, the films were deposited via DC magnetron sputtering in a chamber (Torr International Inc.) with a base pressure $\leq 2 \times 10^{-6} \mathrm{mbar}$ and a deposition pressure in the range $(2-7) \times 10^{-3}$ mbar using a graphite target $\left(99.999 \%\right.$, Lesker) as reported previously. ${ }^{5}$ Annealed amorphous carbon films with no N-doping, which will be denoted an-C, were deposited using an Ar plasma; 
$\mathrm{N}$-doped films, denoted as an-C:N, were prepared using two different fluxes of $\mathrm{N}_{2}$ gas in the deposition chamber: anC:N1 was prepared using $2 \% \mathrm{~N}_{2}$ gas in a total flux of $50 \mathrm{sccm} \mathrm{Ar} / \mathrm{N}_{2}$ during the deposition, whilst $10 \% \mathrm{~N}_{2} / \mathrm{Ar}$ was used for an-C:N2. After deposition, the resulting films were transported directly to a tube furnace and annealed under $\mathrm{N}_{2}$ atmosphere for $1 \mathrm{~h}$ at $900{ }^{\circ} \mathrm{C}$.

Characterization. Electrochemical measurements were carried out using a Metrohm Autolab AUT50324 potentiostat using a 3-electrode setup. A static disk holder (Pine Instruments) enclosing the GC disk with the carbon thin film was used as the working electrode as reported previously. ${ }^{5}$ A Hydroflex hydrogen electrode (Gaskatel) and graphite rod were used as reference and counter electrodes, respectively. The electrochemical cell was a five-necked jacketed cell (Pine Instruments) which had its temperature held constant at $25^{\circ} \mathrm{C}$ using a recirculator. Prior to experiments, the cell was cleaned using Piranha solution $\left(3: 1 \mathrm{H}_{2} \mathrm{SO}_{4}: \mathrm{H}_{2} \mathrm{O}_{2}\right.$ CAUTION: Piranha solution is a strong oxidant which may react explosively with organic solvents and must always be used in a fumehood) followed by rinsing with copious amounts of Millipore water. The cell was then rinsed three times with the electrolyte solution used during the experiment immediately prior to the analysis. Cyclic voltammograms (CVs) were acquired in a potential window of 0.48-1.2 V vs RHE in deaerated solutions of $0.1 \mathrm{M} \mathrm{H}_{2} \mathrm{SO}_{4}$ with and without DA in concentrations ranging from $25 \mu \mathrm{M}$ to $1 \mathrm{mM}$. All voltammograms were taken with $\mathrm{iR}$ compensation using commercial software (NOVA) with the uncompensated resistance of $18 \pm 1$ $\Omega$ determined prior to each experiment using Electrochemical Impedance Spectroscopy (EIS).

$\mathrm{X}$-ray photoelectron spectroscopy (XPS) characterization was performed at $1 \times 10^{-10} \mathrm{mbar}$ base pressure in an ultrahigh-vacuum system (Omicron). The X-ray source was a monochromatized $\mathrm{Al} \mathrm{K} \alpha$ source $(1486.6 \mathrm{eV})$. Spectra were recorded at $45^{\circ}$ takeoff angle with an 
analyser resolution of $0.5 \mathrm{eV}$. Spectra were baseline corrected using a Shirley background and fitted with Voigt functions using commercial software (CasaXPS); atomic percent compositions were determined by calculating peak area ratios after correction by relative sensitivity factors $(\mathrm{C}$ $1 \mathrm{~s}=1.0, \mathrm{~N} 1 \mathrm{~s}=1.8, \mathrm{O} 1 \mathrm{~s}=2.93)$.

Raman spectra were measured in backscattering configuration using a Renishaw 1000 microRaman system equipped with an Ar+ laser for $488 \mathrm{~nm}$ excitation. The incident beam was focused by a Leica microscope with a 50× magnification objective and short-focus working distance; incident power was kept $<2 \mathrm{~mW}$ to avoid sample damage. Spectra were baseline corrected using commercial software prior to analysis (OriginPro 9.1).

Computational Studies. Density functional theory (DFT) calculations reported in this work were carried out using the dispersion corrected hybrid functional $\omega$ B97X-D developed by HeadGordon and Chai, ${ }^{30}$ implemented in the Gaussian09 software package. ${ }^{31}$ The choice of this level of theory is based on the satisfactory results obtained in previous theoretical studies for thermochemistry and for the description of non-covalent interactions. ${ }^{32} \mathrm{H}$ atoms were described using the double- $\zeta$ basis set $6-31 \mathrm{G}(\mathrm{d}, \mathrm{p})$, whereas the same basis set plus diffuse functions was employed to describe the more electronegative $\mathrm{O}$ and $\mathrm{N}$ atoms. Geometry optimizations were performed without imposing any constraints and the nature of all the stationary points was further verified through vibrational frequency analysis. The reported adsorption Gibbs energies $\left(\Delta \mathrm{G}_{\mathrm{ads}}\right)$ were calculated at the experimental temperature of $298 \mathrm{~K}$ and pressure of 1 atm, according to the following equation:

$$
\Delta \mathrm{G}_{\mathrm{ads}}=\mathrm{G}_{\text {surf }+\mathrm{DA}}-\mathrm{G}_{\text {surf }}-\mathrm{G}_{\mathrm{DA}}
$$

where $G_{\text {surf }+D A}, G_{\text {surf }}$, and $G_{D A}$ correspond to the adsorbed DA on the graphene cluster, the clean graphene cluster, and the DA molecule in the gas phase, respectively. 


\section{Results and Discussion}

\section{Chemical and structural characterization of nitrogen-free and nitrogenated electrodes}

Carbon electrodes with and without the presence of nitrogen were prepared via the DC magnetron sputtering protocol described in a previous publication ${ }^{5}$ briefly, sputtering using a $\mathrm{N}_{2} / \mathrm{Ar}$ mixture was used to deposit topographically smooth carbon thin films of thickness $<120 \mathrm{~nm}$ and the total nitrogen content was varied by changing the proportion of $\mathrm{N}_{2}$ in the gas mixture. These carbon thin films were prepared as precursor materials for the annealing treatment and contained two different nitrogen concentrations with approximately $15 \%$ and $35 \%$ N/C at.\% ratio, as previously described. ${ }^{5}$ The sputtered films were then annealed for $1 \mathrm{~h}$ under nitrogen at $900{ }^{\circ} \mathrm{C}$. The nitrogen-free carbon films prepared via this method are referred to as anC throughout this work, whereas the two nitrogenated systems studied are referred to as anC:N1 and anC:N2, which originated from precursors with the lower and higher N-contents, respectively.

The composition of the three different carbon materials was investigated via XPS. Figure 1a shows survey scans for the carbon electrode materials indicating the presence of C 1s ( $\mathrm{ca} .284$ $\mathrm{eV})$ and $\mathrm{O} 1 \mathrm{~s}(\mathrm{ca} .532 \mathrm{eV})$ peaks. The absence of nitrogen peaks from the an-C surface is evident in the survey and in high resolution scans of the $\mathrm{N} 1 \mathrm{~s}$ region between 395 and $405 \mathrm{eV}$ shown in the inset in Figure 1a, thus confirming that an-C is a nitrogen-free material. Both an-C:N electrodes possess a small peak in the $400 \mathrm{eV}$ region, which can be attributed to the presence of nitrogen $^{33-35}$ (also shown in the inset). 

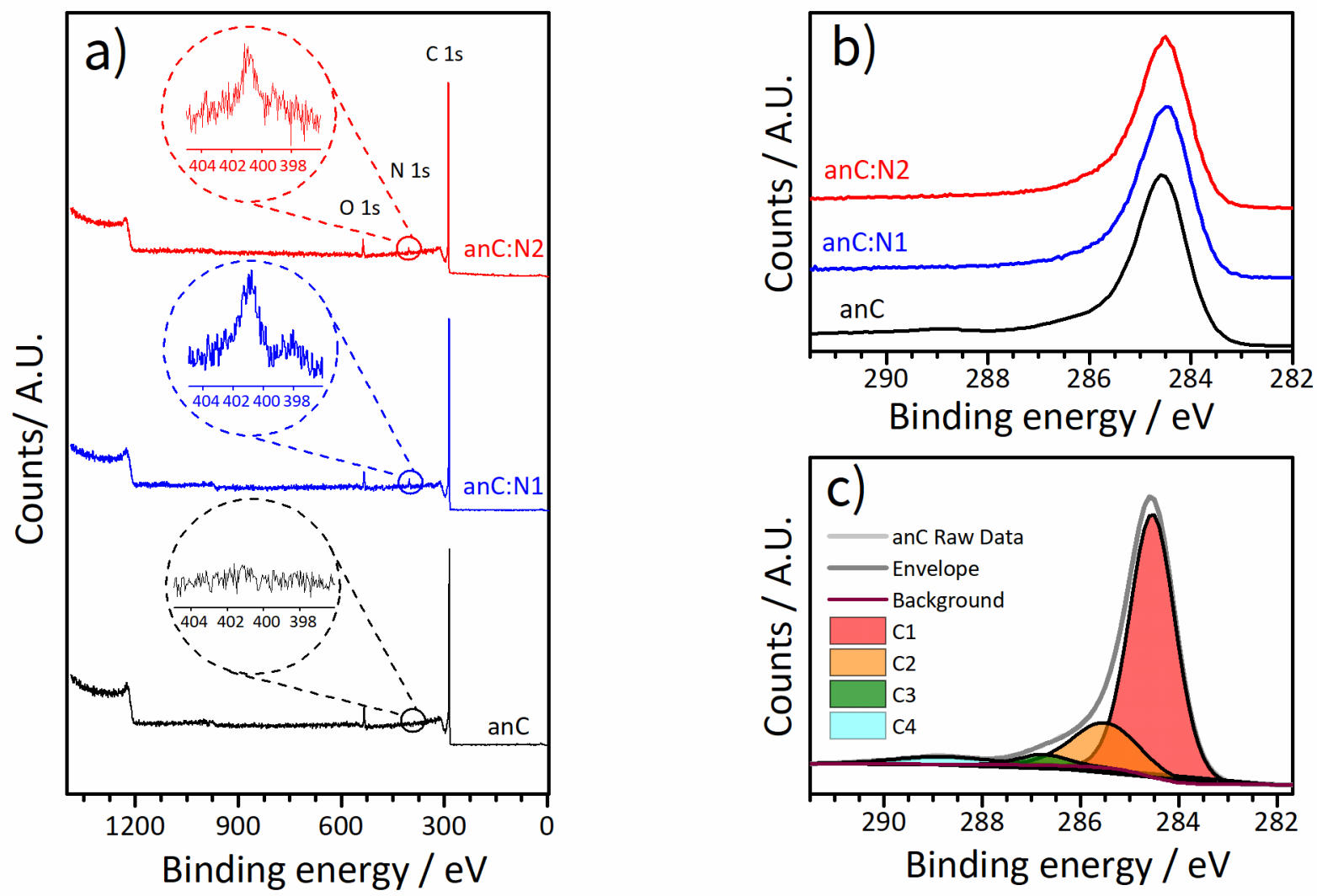

Figure 1. (a) Survey scans of anC, anC:N1 and anC:N2 electrodes. Insets correspond to high resolution scans of the $\mathrm{N} 1 \mathrm{~s}$ regions. (b) High resolution $\mathrm{C}$ 1s scans of anC and anC: $\mathrm{N}$ electrodes. (c) Deconvolution of the $\mathrm{C} 1 \mathrm{~s}$ envelope of anC; the raw data and envelope are offset relative to the components for clarity.

High resolution scans of the $\mathrm{C}$ 1s region are shown in Figure $1 \mathrm{~b}$. The asymmetric envelope indicates that these carbon materials are predominantly based on $\mathrm{sp}^{2}$-bonded carbon, as expected for graphitized carbon surfaces. This was further explored by deconvoluting the $\mathrm{C} 1 \mathrm{~s}$ envelopes, as shown in Figure 1c for the an-C surface, and in Figure $\mathrm{S} 1$ in the supporting information for anC:N materials. The peaks at $c a .284 .5$ and $c a .285 .5 \mathrm{eV}(\mathrm{C} 1$ and $\mathrm{C} 2$ in Figure 1c) are commonly assigned to $\mathrm{sp}^{2}$ and $\mathrm{sp}^{3}$ carbon centres, respectively, ${ }^{36}$ leading to an estimated $\mathrm{sp}^{3} \%$ of $12 \pm 1 \%($ see Table 1$)$ 
Nitrogenation of the carbon scaffold has the effect of increasing the full-width at half maximum (FWHM) of the $\mathrm{C}$ 1s (Table 1) in anC:N samples, which is indicative of the presence of a greater amount of disorder in the carbon $\mathrm{sp}^{2}$-network. ${ }^{37}$ Nitrogen incorporation complicates the determination of the $\mathrm{sp}^{3} / \mathrm{sp}^{2}$ ratio, as the region above $c a .285 .5 \mathrm{eV}$ includes contributions from both $\mathrm{sp}^{3}-\mathrm{C}$ and $\mathrm{sp}^{2}-\mathrm{C}$ bonded to nitrogen. ${ }^{33,35}$ Therefore, we limit the analysis of the $\mathrm{sp}^{3} \%$ determined via XPS to the nitrogen-free anC materials. The peaks at binding energies above $c a$. $286 \mathrm{eV}(\mathrm{C} 3$ and $\mathrm{C} 4$ in Figure 1c) may be assigned to $\mathrm{C}-\mathrm{O}(c a .286 .5 \mathrm{eV})$ and $\mathrm{C}=\mathrm{O}(c a .288 \mathrm{eV})$ in the case of nitrogen-free anC; however, the introduction of nitrogen precludes an unambiguous assignment between $\mathrm{C}-\mathrm{O}$ and $\mathrm{C}-\mathrm{N}$ bonds due to spectral overlap. ${ }^{38}$

The amount of oxygen and nitrogen present in the films was determined from area ratios $\mathrm{A}_{\mathrm{O} 1 \mathrm{~s}} / \mathrm{A}_{\mathrm{Cls}}$ and $\mathrm{A}_{\mathrm{N} 1 \mathrm{~s}} / \mathrm{A}_{\mathrm{Cls}}$, respectively, after correction by sensitivity factors, with the resulting $\mathrm{O} / \mathrm{C}$ and N/C at.\% values reported in Table 1. Analysis of variance (ANOVA) on these data indicate that there is no statistically significant difference in $\mathrm{O} / \mathrm{C}$ at.\% among the three carbon materials $(23 \mathrm{DF}, \mathrm{F}=1.70, \mathrm{p}=0.20)$. Additionally, both anC:N1 and anC:N2 possess statistically identical N/C at.\% (18 DF, $\mathrm{t}=1.85, \mathrm{p}=0.083)$.

Table 1. C 1s FWHM, $\mathrm{sp}^{3} / \mathrm{sp}^{2}$ and chemical composition of anC and anC:N materials obtained from XPS deconvolutions. Errors reported are 95\% confidence intervals.

\begin{tabular}{lcccccc}
\hline Sample & $\mathrm{C} 1 \mathrm{~s}$ FWHM & $\mathrm{sp}^{3} \%$ & $\mathrm{O} / \mathrm{C} \%$ & $\mathrm{~N} / \mathrm{C} \%$ & $\mathrm{~N}_{\mathrm{G}} / \mathrm{N}_{\mathrm{T}} \%$ & $\mathrm{~N}_{\mathrm{P}} / \mathrm{N}_{\mathrm{T}} \%$ \\
\hline anC & $1.00 \pm 0.05$ & $12 \pm 1$ & $3 \pm 2$ & - & - & - \\
anC:N1 & $1.7 \pm 0.4$ & - & $4 \pm 1$ & $1.8 \pm 0.3$ & $75 \pm 5$ & $25 \pm 5$ \\
anC:N2 & $2.1 \pm 0.6$ & - & $2.6 \pm 0.7$ & $2.4 \pm 0.6$ & $74 \pm 8$ & $26 \pm 8$
\end{tabular}


High resolution $\mathrm{N}$ 1s spectra for the anC:N surfaces are shown along with their deconvolution in Figure 2. For both anC:N films, a deconvolution into two major components yielded the best fits. There is a dominant contribution to the envelope at $c a .401 \mathrm{eV}$ which is associated with the presence of graphitic nitrogen $\left(\mathrm{N}_{\mathrm{G}}\right)$, as well as a smaller shoulder at $c a .398 \mathrm{eV}$, which is commonly assigned to pyridinic- $\mathrm{N}\left(\mathrm{N}_{\mathrm{P}}\right) .{ }^{33,34}$ The ratio of $\mathrm{N}_{\mathrm{P}} / \mathrm{N}_{\mathrm{G}}$ is approximately $25: 75$ for both anC:N1 and anC:N2 (Table 1), indicating that both systems possess similar nitrogen site distribution.

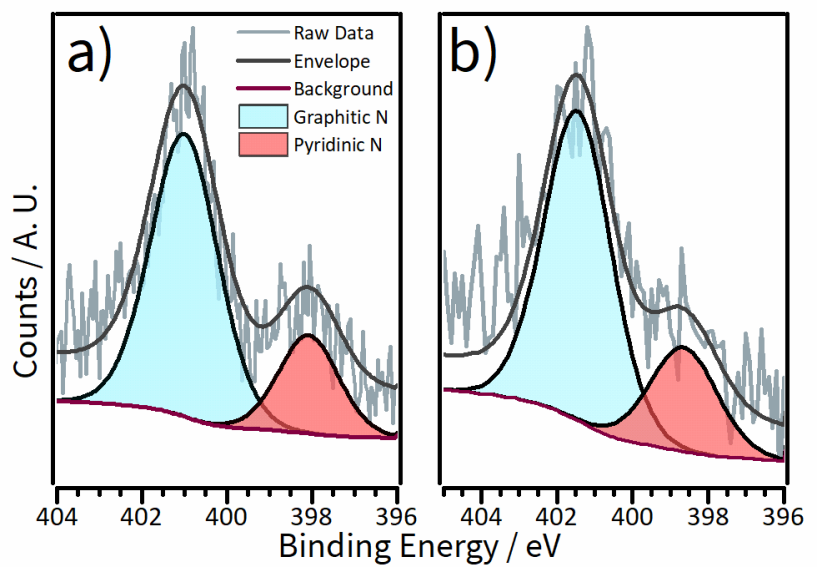

Figure 2. High resolution $\mathrm{N}$ 1s scans of (a) anC:N1, and (b) anC:N2, showing their deconvolution into two contributions; raw data and envelope are offset relative to the components for clarity.

In summary, XPS measurements of anC, anC:N1 and anC:N2 indicate that carbon deposition followed by thermal annealing results in graphitized carbon materials with and without nitrogen incorporation. All three carbon materials possess comparable levels of oxygen, whilst the nitrogenated systems have comparable total nitrogen content and similar distribution of surface $\mathrm{N}$-sites. Despite these similarities, the carbon scaffolds differ significantly as evidenced by the differences observed in C 1s FWHM. 
To probe the differences in the carbon scaffolds of anC and anC:N carbon materials, Raman spectroscopy measurements were carried out at an excitation wavelength of $488 \mathrm{~nm}$. Figure 3a shows background-subtracted Raman spectra for the anC and anC:N films. All spectra show two maxima at $c a .1590 \mathrm{~cm}^{-1}$ and $1380 \mathrm{~cm}^{-1}$, assigned to the $\mathrm{G}$ and $\mathrm{D}$ peaks of $\mathrm{sp}^{2}-\mathrm{C}$ centers, respectively. ${ }^{37,39-40}$ The $\mathrm{G}$ peak is associated with an in-plane stretching mode of $\mathrm{sp}^{2}$-C centres present in the carbon scaffold, whereas the D peak is a breathing mode of $\mathrm{sp}^{2}-\mathrm{C}$ sites in sixmembered rings $;{ }^{39}$ the $\mathrm{D}$ peak is normally forbidden in perfectly crystalline graphite but is active in the presence of disorder/defects.
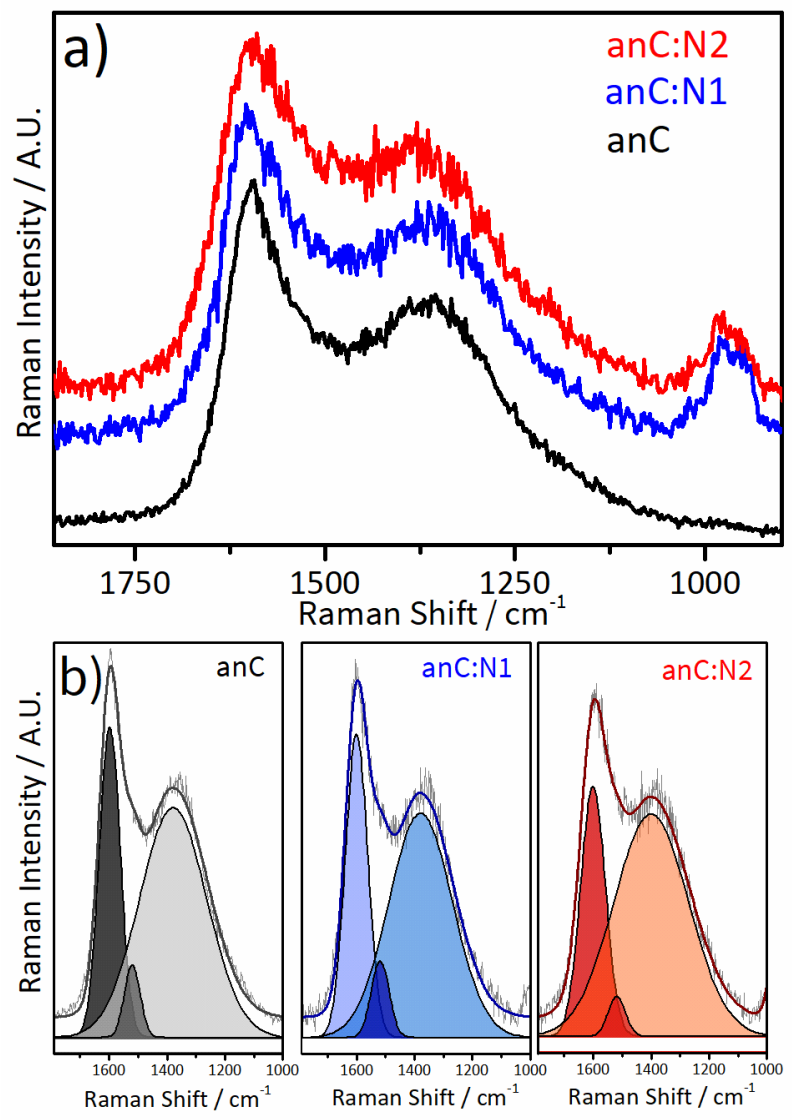

Figure 3. (a) Raman spectra of anC and anC-N carbons; spectra are background corrected and offset for clarity. (b) Deconvolution of anC, anC:N1 and anC:N2 spectra. 
The best fits for the anC and anC:N spectra were obtained using a 3 peak Gaussian deconvolution involving the aforementioned $\mathrm{G}$ and $\mathrm{D}$ peaks as well as a third smaller peak close to $1500 \mathrm{~cm}^{-1}$ (Figure $3 \mathrm{~b}$ ). The latter is commonly referred to as the A peak and is associated with C-C stretching vibrations in an amorphous carbon network, where both three- and fourcoordinated carbon atoms exist in the regions connecting graphitic crystallites. ${ }^{41}$ The small peak close to $1000 \mathrm{~cm}^{-1}$ observed in some spectra is associated with the Si substrate on which the films were deposited for Raman characterization. ${ }^{42}$ Spectral parameters derived from the fits are reported in Table 2 .

Table 2. Raman spectral parameters for anC and anC:N carbon materials.

\begin{tabular}{cccllll}
\hline Sample & $\mathrm{I}_{\mathrm{D}} / \mathrm{I}_{\mathrm{G}}$ & $\mathrm{I}_{\mathrm{A}} / \mathrm{I}_{\mathrm{G}}$ & $\begin{array}{l}\mathrm{G} \text { position / } \\
\mathrm{cm}^{-1}\end{array}$ & $\begin{array}{l}\mathrm{G} \mathrm{FWHM} \mathrm{/} \\
\mathrm{cm}^{-1}\end{array}$ & $\begin{array}{l}\mathrm{D} \text { position / } \\
\mathrm{cm}^{-1}\end{array}$ & $\begin{array}{l}\mathrm{D} \mathrm{FWHM} / \\
\mathrm{cm}^{-1}\end{array}$ \\
\hline anC & 0.74 & 0.23 & 1598 & 85 & 1379 & 274 \\
anC:N1 & 0.73 & 0.26 & 1600 & 91 & 1379 & 260 \\
anC:N2 & 0.84 & 0.16 & 1603 & 104 & 1385 & 279
\end{tabular}

On the basis of the three-stage model of Ferrari and Robertson for amorphous carbons with and without nitrogen, ${ }^{37,} 39$ all three carbon materials have properties that are closer to nanocrystalline graphite than to amorphous carbon. This is evidenced by a G-peak position at $c a$. $1600 \mathrm{~cm}^{-1}$ for all three model systems and a FWHM that suggests a cluster size $<10 \mathrm{~nm} .{ }^{37}$ For anC:N1 and anC:N2, the G FWHM increases relative to nitrogen-free anC, with anC:N2 having the widest FWHM and therefore the greatest disorder. Further insights on the carbon microstructure emerge from an analysis of $\mathrm{I}_{\mathrm{D}} / \mathrm{I}_{\mathrm{G}}$ and $\mathrm{I}_{\mathrm{A}} / \mathrm{I}_{\mathrm{G}}$ ratios, also shown in Table 2, which are diagnostic of the degree of order/disorder. The anC:N1 has slightly smaller $\mathrm{I}_{\mathrm{D}} / \mathrm{I}_{\mathrm{G}}$ and slightly 
$\operatorname{larger} \mathrm{I}_{\mathrm{A}} / \mathrm{I}_{\mathrm{G}}$ ratios relative to unmodified carbon, although the differences are relatively small and do not suggest significant differences between anC and anC:N1 in terms of the organization of the carbon scaffold and the density of defects/boundaries. In the case of anC:N2, however, the $\mathrm{I}_{\mathrm{D}} / \mathrm{I}_{\mathrm{G}}$ is significantly larger than anC:N1, which is strongly suggestive of a smaller average crystallite size for the graphitic clusters. This is consistent with anC:N2, which shows the smallest $\mathrm{I}_{\mathrm{A}} / \mathrm{I}_{\mathrm{G}}$ ratio, indicating that graphitized regions of the scaffold are more closely packed, thus reducing the prevalence of interstitial C-C contributions.

Overall, Raman data indicate that anC:N1 and anC:N2 display significant differences in the organization of their carbon scaffolds, despite these materials possessing identical N/C at.\% and comparable concentration of $\mathrm{N}_{\mathrm{G}}$ and $\mathrm{N}_{\mathrm{P}}$ sites. The fact that $\mathrm{N}_{\mathrm{P}}$ remains constant between anC:N1 and anC:N2 is intriguing, since $\mathrm{N}_{\mathrm{P}}$ necessarily exists at edge or vacancy sites in the carbon scaffold. The increase in disorder for anC:N2 can therefore only be explained on the basis of differences in the organization of the carbon framework around these $\mathrm{N}$-sites, rather than on the basis of $\mathrm{N}_{\mathrm{G}}$ and $\mathrm{N}_{\mathrm{P}}$ concentration changes. We believe that dissimilarities in carbon scaffold structuring likely arise from the use of precursor sputtered materials that possess different initial $\mathrm{N} / \mathrm{C}$ contents (15 and 35 at.\%), as previously mentioned. It is well known that annealing of nitrogenated carbon systems at temperatures above $800{ }^{\circ} \mathrm{C}$ selects for the most thermally stable $\mathrm{N}_{\mathrm{G}}$ sites. ${ }^{8}$ This explains the evolution of both an-C:N materials towards almost identical N-site composition and concentration, i.e. the majority of the initial nitrogen content is "annealed-out" resulting in a final concentration $<2.5$ at. $\%$ of predominantly $\mathrm{N}_{\mathrm{G}}$-sites. However, the initial concentration of edges, defects and $\mathrm{N}$-sites determines the level of clustering present prior to annealing, which limits the ability to "anneal-out" carbon defects. Hence, disorder in the 
precursor carbon seems to influence the final concentration of residual vacancies and the degree of graphitic clustering/ordering achieved post-annealing.

\section{Voltammetric Studies of anC and anC:N}

Based on XPS and Raman results, anC and anC:N1 possess similar degrees of graphitization in their carbon scaffold but differ in that anC:N1 displays $\mathrm{N}_{\mathrm{G}} / \mathrm{N}_{\mathrm{P}}$ functionalities on its surface. On the other hand, anC:N1 and anC:N2 possess indistinguishable $\mathrm{N}_{\mathrm{G}} / \mathrm{N}_{\mathrm{P}}$ composition but display differences in the nanostructuring of their graphitic clusters. Despite the presence of numerous structure-activity studies on nitrogenated carbons, there has been a disproportionate amount of attention paid to identifying particular $\mathrm{N}$-sites and correlating activities to their presence or absence, ${ }^{6,16}$ with less emphasis placed on how the local environment of these sites may be organized. The materials discussed in the previous section offer an opportunity to investigate the effect of graphitic cluster organization on the response of a solid carbon electrode with controlled $\mathrm{N}$-functional group type and concentration, while allowing to discriminate contributions arising from the presence of $\mathrm{N}$-functionalities at the surface. In this context, redox couples have been used as probes of carbon electrode properties by our group and others in the literature. ${ }^{5,43-44}$ To probe the effect of surface nanostructuring on the electrochemical response of nitrogenated graphitic carbons, we selected a catechol species as a redox probe, as these are known to be surface-sensitive and adsorb onto carbon electrodes. ${ }^{17-18,44}$

Catechols display redox chemistry that is highly sensitive to surface preparations, ranging from polishing and cleaning protocols to modification with adlayers. ${ }^{45-46}$ In particular, recent work by Patel et $a l .{ }^{47}$ using dopamine demonstrated a strong dependence of the redox response on carbon electrode edge/plane exposure, while work by Gai et al. and Sheng et al. on nitrogenated carbons showed a range of redox behaviour that suggests high sensitivity to chemical and structural 

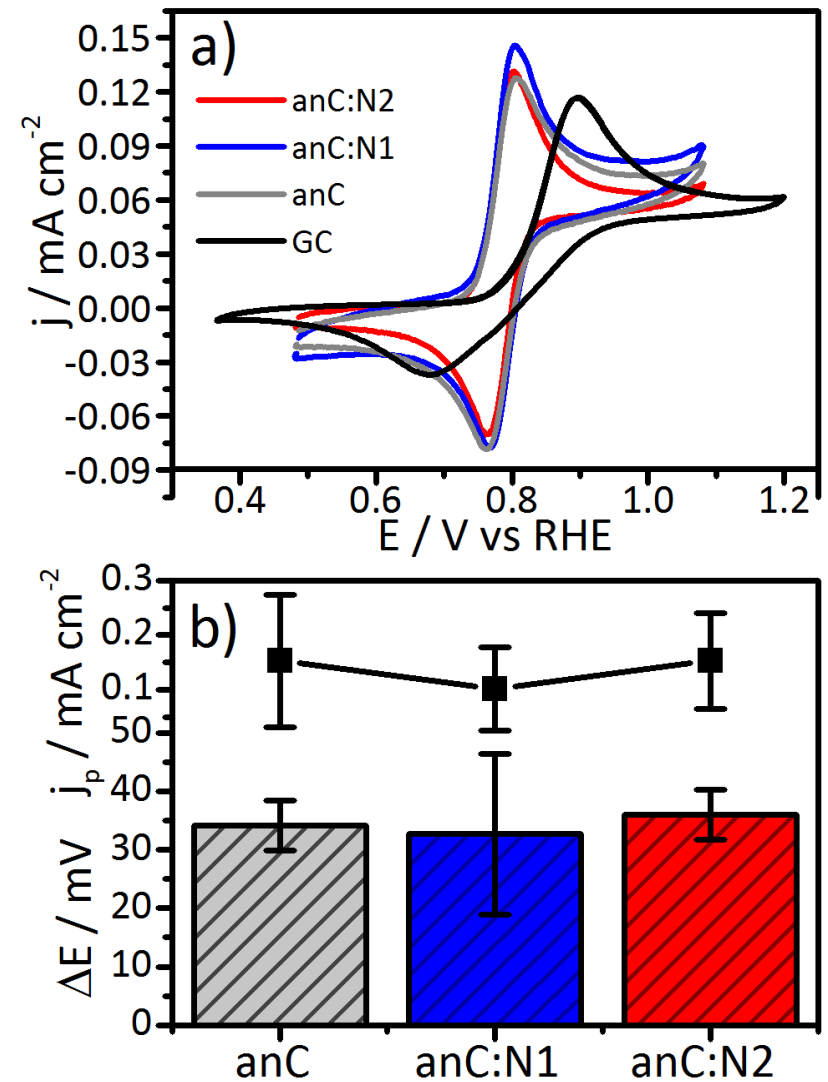

Figure 4. (a) CVs of GC, anC and anC: $\mathrm{N}$ films in solutions of $1.0 \mathrm{mM} \mathrm{DA} / 0.1 \mathrm{M} \mathrm{H}_{2} \mathrm{SO}_{4}$ at 5 $\mathrm{mV} \mathrm{s}^{-1}$. (b) Peak current densities (top) and $\Delta \mathrm{E}$ values (bottom) derived from voltammetric measurements at $5 \mathrm{mV} \mathrm{s}^{-1}$ on all annealed electrodes studied.

changes. ${ }^{25-26}$ These observations led us to speculate that DA redox reactions might be facilitated by $\pi$-stacking interactions at amorphous/disordered carbon surfaces, which could in principle be used as a probe for the degree of clustering and organization of the carbon scaffold surrounding $\mathrm{N}$-sites.

Figure 4a shows representative CVs in $1.0 \mathrm{mM}$ DA solutions in $0.1 \mathrm{M} \mathrm{H}_{2} \mathrm{SO}_{4}$ for anC, anC:N1 and anC:N2 electrodes at a scan rate $(v)$ of $5 \mathrm{mV} \mathrm{s}^{-1}$. For comparison, the voltammogram of a polished glassy carbon (GC) disk is also presented. The oxidation of DA involves a net transfer of two protons and two electrons $(n=2)$ via a complex 'scheme of squares' mechanism. ${ }^{17}{ }^{48}$ The $\mathrm{CVs}$ in Figure 4a have the characteristics of a reversible $2 \mathrm{e}^{-}$process, with $\Delta \mathrm{E}$ values close to the 
Nernstian value of $\frac{59}{2} \mathrm{mV}^{49}$ and almost identical anodic and cathodic peak current densities (Figure 4b). By contrast, the DA voltammogram on the GC disk shows a large peak-to-peak separation of $240 \pm 60 \mathrm{mV}$ which is consistent with irreversible charge transfer kinetics. ${ }^{50}$

anC and anC:N electrodes show indistinguishable behaviour towards $\mathrm{DA}$ close to the reversible charge transfer limit, at low scan rates. However, significant differences emerge among the three materials as the scan rate is increased from 50 to $1000 \mathrm{mV} \mathrm{s}^{-1}$ (Figures $5 \mathrm{a}-\mathrm{c}$ ). The shape of the voltammetric waves is markedly different from that observed at low scan rates in Figure 4a, becoming more symmetric in shape, a feature indicative of the presence of an
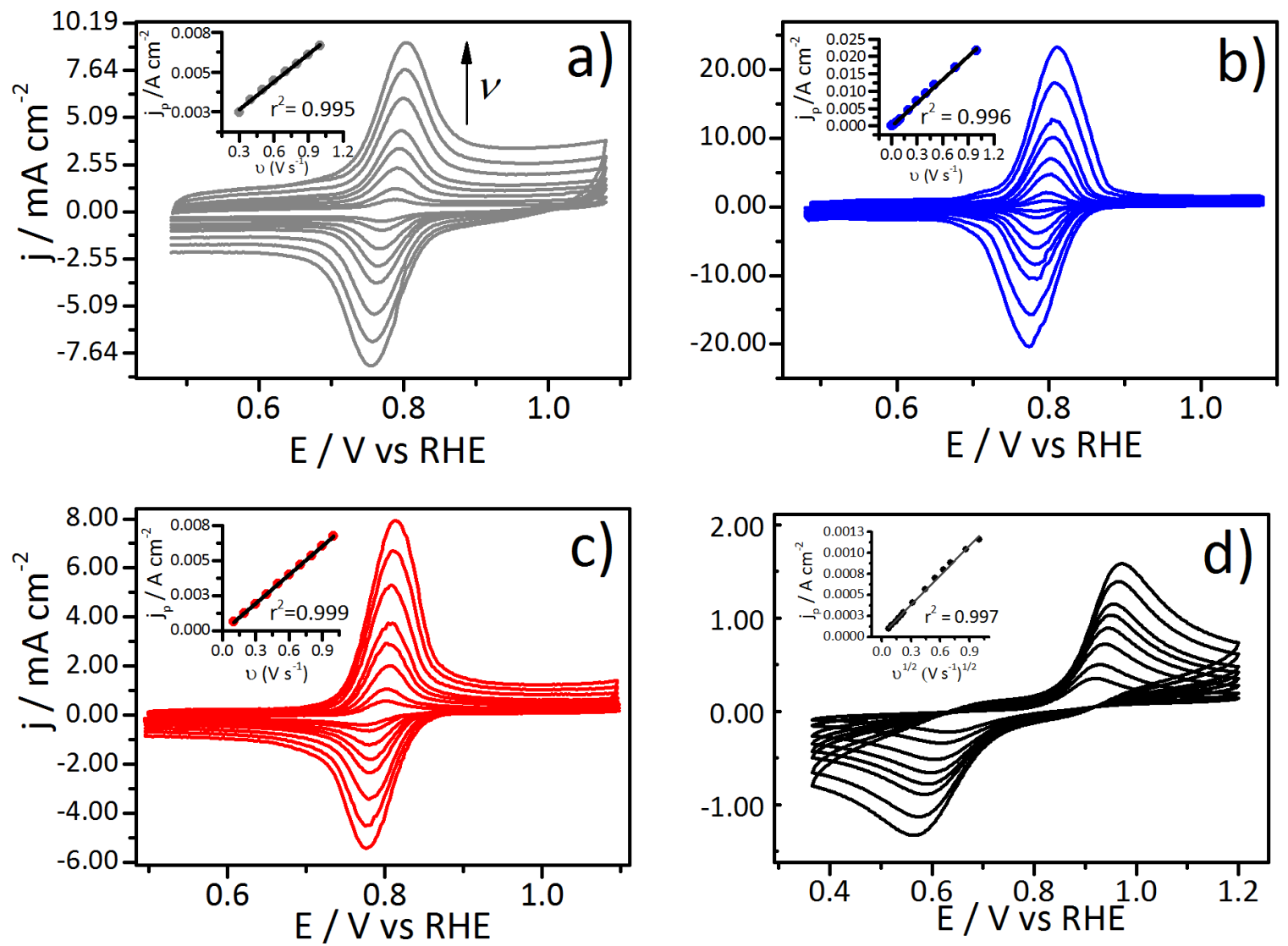

Figure 5. CVs of $1.0 \mathrm{mM}$ DA in $0.1 \mathrm{M} \mathrm{H}_{2} \mathrm{SO}_{4}$ for (a) anC, (b) anC:N1, (c) anC:N2 and (d) GC electrodes; $v=50-1000 \mathrm{mV} \mathrm{s}^{-1}$. Insets in (a)-(c) are plots of peak current density $\left(j_{p}\right)$ vs. $v$, showing a linear relationship. The inset in (d) corresponds to a plot of $j_{p}$ vs. $v^{1 / 2}$. 
adsorbed redox species at the surface. ${ }^{46,50} \Delta \mathrm{E}$ values in Figures 5a-c are in the range of 10-20 $\mathrm{mV}$, characteristic of an adsorption-controlled process, for which peak-to-peak potential values are expected to approach zero. A direct comparison of the current functions at low and high scan rate presented in Figure S2 (see Supporting Information) clearly shows these waveform changes. Plots of anodic peak current density, $j_{p}$, vs. $v$ in the insets of Figures 5a-c show that $j_{p}$ varies linearly in the range of $50-1000 \mathrm{mV} \mathrm{s}^{-1}$, which is consistent with a surface-adsorbed redox probe. For the bare GC (Figure 5d), we found that there is no evidence of a narrowing of $\Delta \mathrm{E}$ or an enhancement of $j_{p}$, which increases linearly vs. $v^{1 / 2}$, as expected for a diffusive process which is uncomplicated by the presence of adsorbed reactant.

Changes in waveform and peak separation indicate that both solution-phase and surface-bound DA are redox active, with adsorbed DA contributing more to the overall peak current as the scan rate increases. ${ }^{51}$ This is clearly evident from a logarithmic plot of anodic peak current $\left(i_{p, a}\right)$ vs. scan rate for the an- $\mathrm{C}$ and an-C:N electrodes presented in Figure 6a, which shows a slope of $m=$ 0.5 at scan rates of $5-20 \mathrm{mV} \mathrm{s}^{-1}$. This suggests that oxidation of DA in solution dominates the Faradaic current in this range as described by equation (1), ${ }^{52}$ where $A$ is the electrode area, $D$ is the diffusion coefficient, and $c$ is the concentration of DA. For higher scan rates, there is an enhancement of $i_{p}$ above the value expected for a Nernstian process such that each of the plots diverges from $m=0.5$ and approaches a slope $m=1$. This suggests that the response in this scan range is better described by equation $(2)^{53}$ and its logarithmic form in equation (3), where the Faradaic current is assumed to originate from a redox species bound at the electrode with a surface coverage $\Gamma$. 

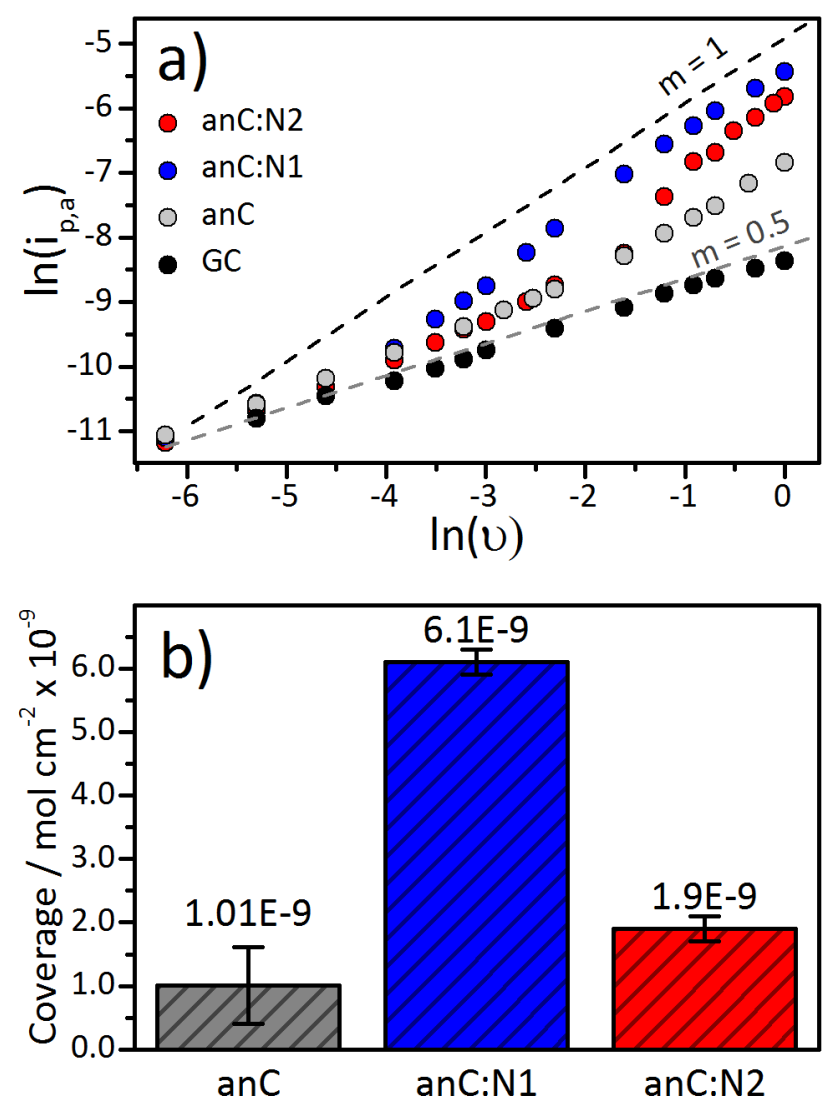

Figure 6. (a) Logarithmic plot of the anodic peak current, $i_{p, a}$, vs. $v$, for anC and anC:N electrodes in a solution of $1.0 \mathrm{mM} \mathrm{DA}$ in $0.1 \mathrm{M} \mathrm{H}_{2} \mathrm{SO}_{4}$. The dashed lines represent theoretical slopes of $m=1$ and $m=0.5$ and are present to guide the eye. (b) Coverage values, $\Gamma$, of DA on the electrode surfaces calculated using equation (2) in the text.

$$
\begin{aligned}
& \ln \left(i_{p}\right)=0.5 \ln (v)+\ln \left(2.69 .10^{5} n^{\frac{3}{2}} A D^{\frac{1}{2}} c\right) \\
& i_{p}=\frac{n^{2} F^{2} v A \Gamma}{4 R T} \\
& \ln \left(i_{p}\right)=\ln (v)+\ln \left(\frac{n^{2} F^{2} A \Gamma}{4 R T}\right)
\end{aligned}
$$

Using the slopes obtained from the plots in the insets of Figure 5, along with equation (2) with $T=298 \mathrm{~K}$ and the electrode geometric area $A=0.1963 \mathrm{~cm}^{2}$, the DA coverages $\left(\Gamma_{\mathrm{DA}}\right)$ at each electrode surface were obtained and are summarized in Figure 6b. From this figure, it is evident that there are significant differences in $\Gamma_{D A}$ among the three carbon electrodes, which were found 
to be in a ratio of 1.0:6.0:1.9 for anC : anC:N1 : anC:N2. From the voltammograms it is also possible to estimate the effects of lateral interactions between adsorbed DA by examining the full-width at half maximum (FWHM) of the peaks. ${ }^{54}$ The results of this analysis are reported in Table S1 and suggest the presence of only weak lateral interactions.

The differences in $\Gamma$ cannot be explained based on changes to the electrochemical surface area (ESA) among the three electrodes. This was confirmed based on measurements of specific capacitance in supporting electrolyte solution, which did not afford statistically significant differences in capacitance among the three electrodes (see Supporting Information). This suggests that differences in the ESA cannot explain the trend in Figure 6b, and that specific DAsurface interactions vary among anC, anC:N1 and anC:N2, thus giving rise to marked differences in adsorption yields.

It is interesting to examine $\Gamma_{D A}$ results in the light of chemical and structural information obtained via XPS and Raman. Nitrogen incorporation into the anC:N electrodes in the form of $\mathrm{N}_{\mathrm{G}} / \mathrm{N}_{\mathrm{P}}$ functional groups results in enhanced $\Gamma_{D A}$ relative to anC, which likely stems from a combination of chemical and physical effects on DA adsorption at the carbon surface. The similarities between anC:N1 and anC:N2 in terms of $\mathrm{N} / \mathrm{C}$ and $\mathrm{O} / \mathrm{C}$ content and proportion of $\mathrm{N}_{\mathrm{P}} / \mathrm{N}_{\mathrm{G}}$ functionalities (see Table 1) suggest that fundamental physical/structural differences, rather than differences in chemical functionality, might better explain the 3-fold enhancement of $\Gamma_{D A}$ for anC:N1 relative to anC:N2. Furthermore, the more modest 2-fold enhancement of $\Gamma_{D A}$ in anC:N2 compared to anC suggests that physical/structural effects can have a stronger effect on DA adsorption than the presence of $\mathrm{N}_{\mathrm{G}} / \mathrm{N}_{\mathrm{P}}$ surface functional groups. This conclusion is supported by our Raman results, which indicate that anC and anC:N1 are similar in their organization of the carbon scaffold and their degree of graphitization, while anC:N2 displays the 
most disordered carbon structure and likely the smallest crystallite size among the three graphitic materials. The introduction of $\mathrm{N}_{\mathrm{G}} / \mathrm{N}_{\mathrm{P}}$ groups without a significant disruption of the graphitic scaffold results in an enhancement of $\Gamma_{D A}$ when going from anC to anC:N1. However, this chemical enhancement effect is essentially lost when the degree of graphitization is reduced in anC:N2 materials, i.e. due to changes in the carbon nanostructure.

\section{Computational studies of DA adsorption on graphene models}

Electrochemical results suggest that DA adsorption can track changes in the surface chemistry and nanostructure of graphitic carbon electrodes. Given the similarities in the degree of graphitization between anC and anC:N1, it appears that probe adsorption is enhanced by the incorporation of $\mathrm{N}$-sites, so long as the disruptive effect of nitrogenation does not result in a high concentration of defects in the annealed structure. Probe adsorption at the carbon surface reflects differences in (bulk) defect density between anC:N1 and anC:N2 as observed via Raman spectroscopy, thus suggesting that increased defects in the nitrogenated scaffold can result in reduced probe adsorption. Hence, the combination of spectroscopic and voltammetric results led us to hypothesise that DA adsorption may serve as an indicator of the degree of graphitization at the electroactive interface in nitrogenated carbons.

With the aim of providing a better understanding of the interaction between DA and the different graphitic surfaces, we carried out a computational investigation at the DFT-wb97xd level (see details in SI) using the model graphene structures presented in Figure 7. While graphene and $\mathrm{N}$-graphene with vacancies have been studied theoretically, ${ }^{22-23}$ to our knowledge this is the first time that DFT calculations have been used to evaluate the interaction of DA with graphitic edges, and the first to take into account the entropic contributions to the adsorption by computing the Gibbs free energy of adsorption, $\Delta \mathrm{G}_{\mathrm{ads}}$. 

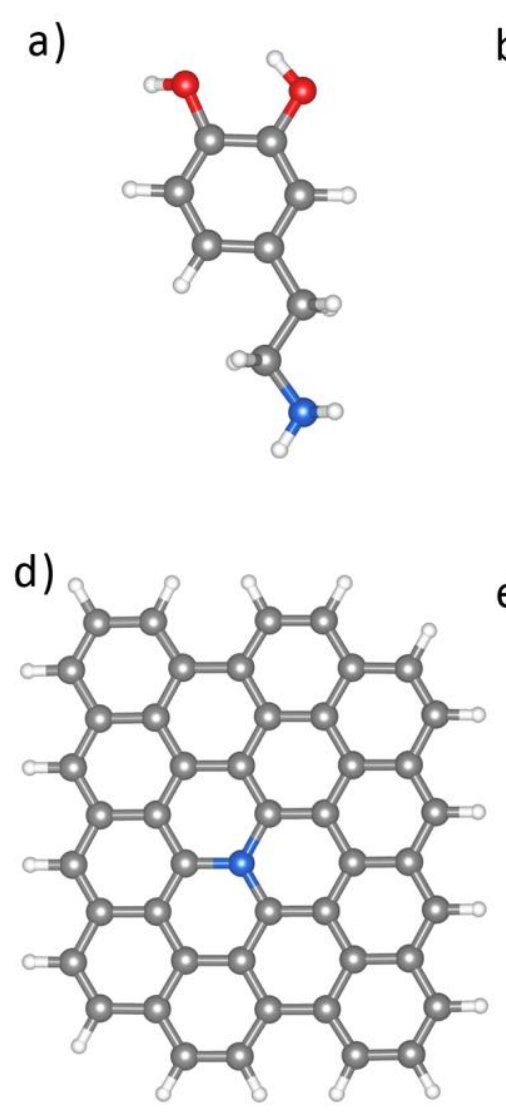

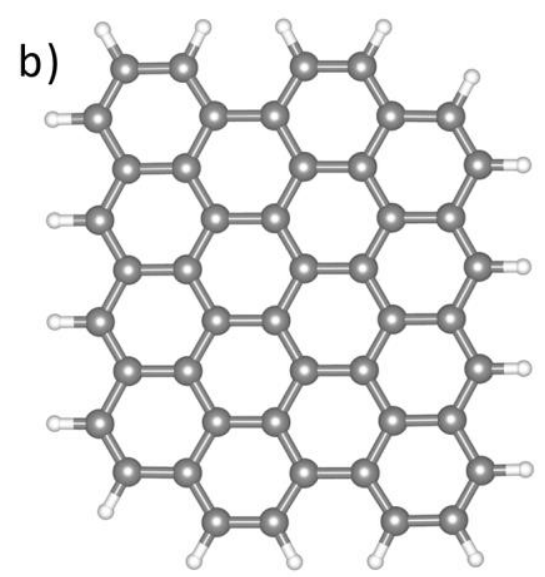

e)

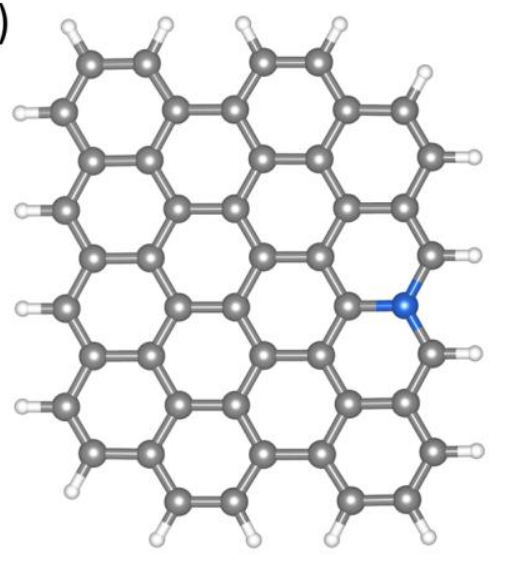

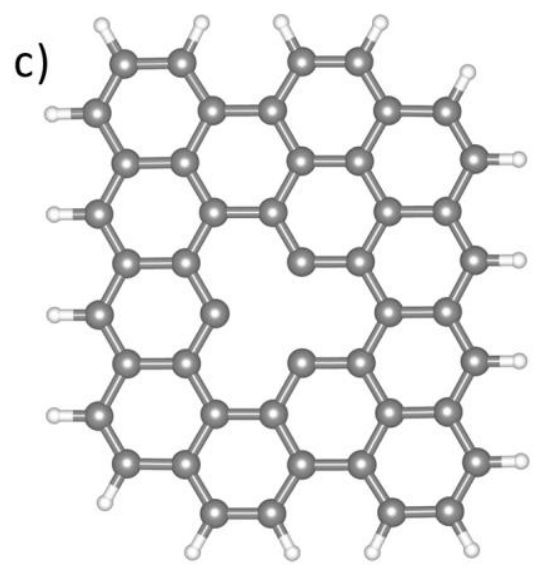

f)

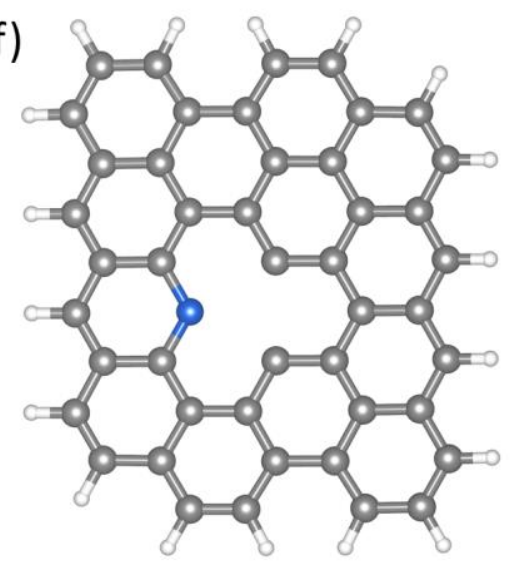

Figure 7. Ball and stick representation of the DFT-modelled structures: (a) DA, (b) graphene, (c) graphene with a single carbon vacancy, (d) N-graphene with a graphitic centre site, (e) Ngraphene with a graphitic valley site, and (f) $\mathrm{N}$-graphene with a pyridinic vacancy.

We started our computational analysis by optimising the structures of the isolated DA molecule and the graphitic model surfaces shown in Figure 7, followed by the adsorption of DA on the different surfaces taking into account all the possible orientations and adsorption sites. The lowest $\Delta \mathrm{G}_{\mathrm{ads}}$ values obtained and the corresponding structures are summarized in Figure 8. All the modelled structures showing a less favourable adsorption energy are illustrated in detail in the Supporting Information, Figures S4-S11. 
a)

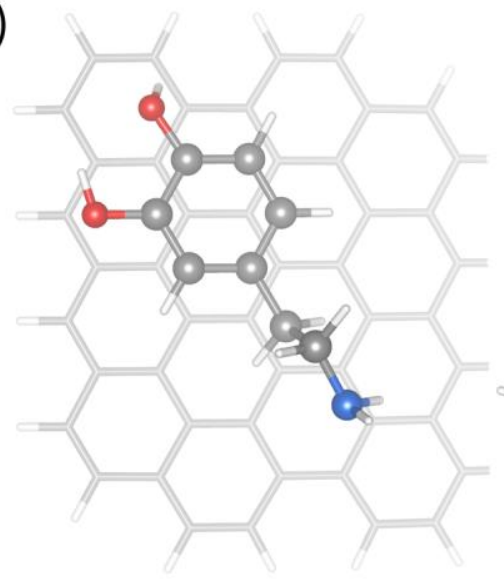

b)
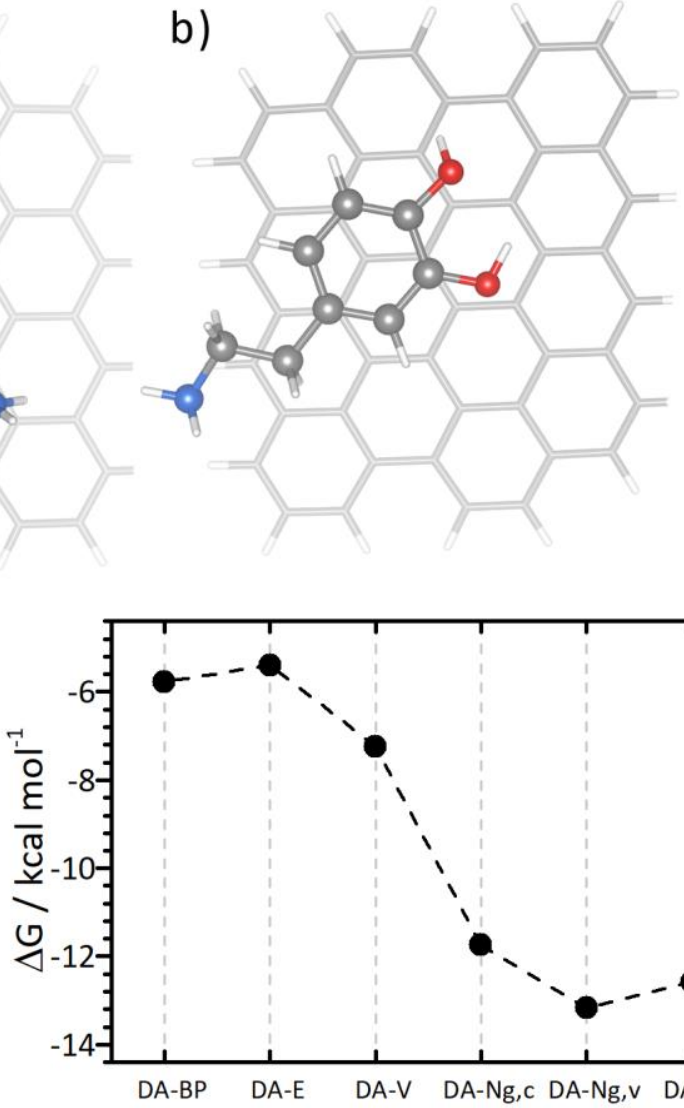

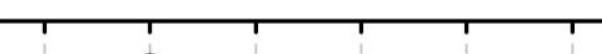

d)

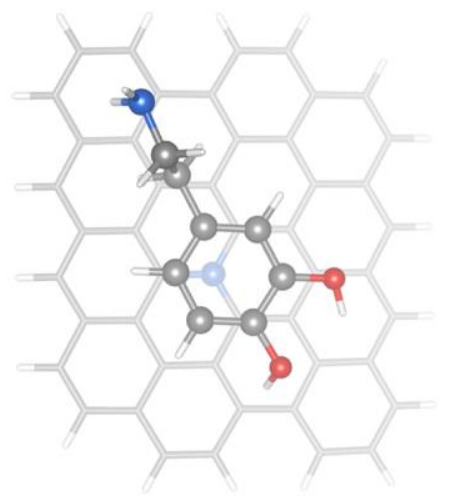

e)

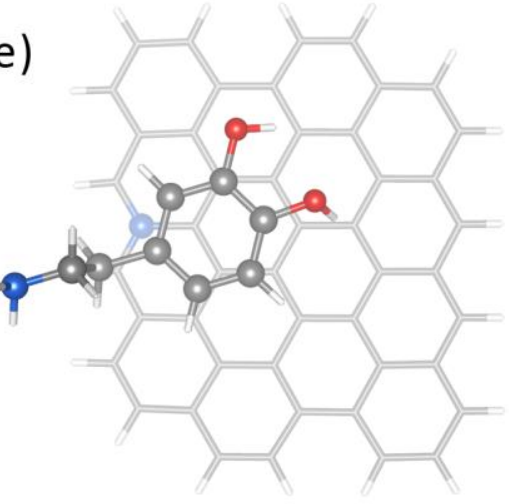

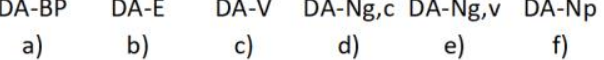

f) c)
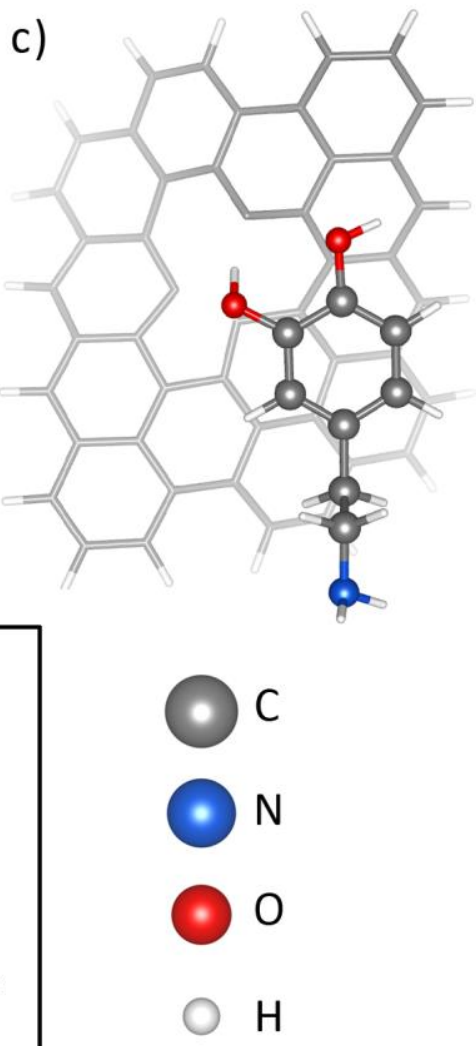

- N

0

$\mathrm{H}$

$$
\text { f) }
$$

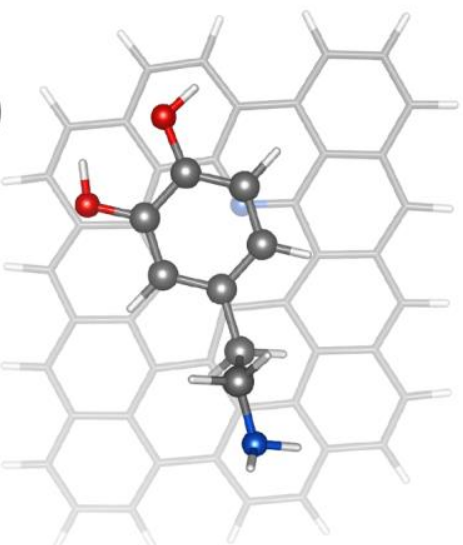

Figure 8. Calculated adsorption Gibbs energies $\left(\Delta \mathrm{G}_{\mathrm{ads}}\right)$, in $\mathrm{kcal} \mathrm{mol}^{-1}$ for DA. Top views of the optimized structures for the different adsorption modes and their corresponding $\Delta \mathrm{G}_{\mathrm{ads}}$ values on graphene (a-c) and N-doped graphene (d-f) model systems.

For the interaction of DA with the basal plane of pristine graphene (DA-BP), we found that the most favourable orientation of the molecule at the surface is close to parallel, with a ring-surface 
distance of 3.2-3.6 $\AA$ (Figure 8a). This range of bond distances are typical of non-covalent interactions and are in line with those reported in previous theoretical studies for DA adsorption on graphene. ${ }^{23}$ In this adsorption mode, the ethylamine chain is oriented away from the benzene ring, giving a distance of around $4.6 \AA$ between the N-atom of the amine and the surface. The interaction of DA with the lone pair of the amine pointing to a hydrogenated graphene edge and the aromatic ring facing away from the surface was also considered (DA-E). According to our calculations, this adsorption mode is not stable and the DA molecule evolves to an orientation parallel to the basal plane as for DA-BP (Figure 8b). However, unlike DA-BP, the ethylamine group in DA-E is placed in an almost parallel disposition to the surface close to a hydrogenated edge atom, with a $\mathrm{N}$-surface distance of $3.3 \AA$. While this might be indicative of a weak interaction between the edge site and the lone pair of the amine, the computed $\Delta \mathrm{G}_{\text {ads }}$ for DA-E is almost identical to DA-BP ( -5.4 and $-5.5 \mathrm{kcal} / \mathrm{mol}$, respectively). Hence, for hydrogenated edges, we conclude that there is no clear preference in the orientation of the amine when the $\pi$ system of DA interacts with the basal plane. Likewise, the DA molecule adsorbed on a carbon vacancy $(\mathrm{DA}-\mathrm{V})$ is also oriented parallel to the graphene surface, but in this case the $\mathrm{H}$ atoms from the hydroxyl groups point into the vacancy (Figure 8c). The $\Delta \mathrm{G}_{\text {ads }}$ value obtained for DA-V is approximately $2 \mathrm{kcal} \mathrm{mol}^{-1}$ lower than DA-BP and DA-E, which may be explained by the favourable interactions arising from the hydrogen bonding between the hydroxyl groups and the unsaturated carbon atoms adjacent to the vacancy.

When moving to the $\mathrm{N}$-doped graphene surfaces (Figures $8 \mathrm{~d}-\mathrm{f}$ ), we found that $\Delta \mathrm{G}_{\text {ads }}$ becomes significantly more negative compared to the aforementioned non-nitrogenated surfaces. In the case of DA- $\mathrm{N}_{\mathrm{G}, \mathrm{C}}$, the orientation of DA is almost identical to that of non-nitrogenated DA-BP, with the $\pi$-system of DA sitting on top of the graphitic nitrogen $\left(\mathrm{N}_{\mathrm{G}}\right)$ and with a $\mathrm{N}$-surface 
distance of $4.66 \AA$ (Figure $8 \mathrm{~d}$ ). Interestingly, the calculated $\Delta \mathrm{G}_{\mathrm{ads}}$ for DA-N $\mathrm{N}_{\mathrm{G}, \mathrm{C}}$ is more than double the value of the DA-BP interaction $\left(-11.7\right.$ vs. $\left.-5.5 \mathrm{kcal} \mathrm{mol}^{-1}\right)$, thus suggesting that the substitutional $\mathrm{N}$-site enhances adsorption of the DA molecule. The most negative $\Delta \mathrm{G}_{\text {ads }}$ value, however, was obtained for DA- $\mathrm{N}_{\mathrm{G}, \mathrm{V}}$, where DA sits parallel to the surface over the $\mathrm{N}_{\mathrm{G}, \mathrm{V}}$ site with the amine pointing away from the surface (Figure 8e). A similar adsorption energy was obtained even when the molecule was oriented with the amine pointing at the nitrogenated edge (Figure S10). Finally, for the interaction of DA with the carbon surface containing a pyridinic vacancy $\left(\mathrm{DA}-\mathrm{N}_{\mathrm{P}}\right)$, we found that the aromatic ring of DA sits on top of the pyridinic nitrogen site $\left(\mathrm{N}_{\mathrm{P}}\right)$ with the amine group almost parallel to the surface (Figure $8 \mathrm{f}$ ). The calculated $\Delta \mathrm{G}_{\text {ads }}$ for this structure is only slightly more positive than for $\mathrm{DA}-\mathrm{N}_{\mathrm{G}, \mathrm{V}}$, which indicates that DA adsorption at a pyridinic vacancy is also highly favourable.

Overall, the above DFT results are in good agreement with the voltammetric experiments for both anC and anC:N surfaces, which are strongly suggestive of a weak adsorption at the carbon surface. This is based on the fact that, for a strong adsorption $\left(\Delta \mathrm{G}_{\mathrm{ads}}\right.$ in the absence of an applied field, $\left.\left|\Delta \mathrm{G}_{\text {ads }}^{\circ}\right|>\sim 10 \mathrm{kcal} \mathrm{mol}^{-1}\right)$, 'pre-peaks' and/or 'post-peaks' are expected to appear in the voltammogram due to the strong interaction of the reactant and/or products with the surface. ${ }^{51}$ Our DFT-calculated values of $\Delta \mathrm{G}_{\mathrm{ads}}$ for DA-BP, DA-E and DA-V, are either comparable to this threshold value or lower. On the other hand, our DFT results predict the adsorption at nitrogenated sites to be stronger, although these sites make up a very small proportion of the available binding sites at the surface, as shown in the XPS measurements. Therefore, the absence of any pre- or post-peaks in the voltammograms of anC:N1 and anC:N2 may thus be explained by the low concentration of these sites at the surface. 
The more negative values of $\Delta \mathrm{G}_{\mathrm{ads}}$ at nitrogen sites may partially explain why DA coverages are higher for the anC:N surfaces compared to anC, since adsorption at nitrogen sites is thermodynamically more favourable in N-doped surfaces. However, N-sites alone do not control DA adsorption in general, since anC:N2 has a DA coverage which is far lower than for anC:N1, despite having an identical $\mathrm{N} / \mathrm{C}$ at.\% and $\mathrm{N}$ surface chemistry. This suggests that the mere presence of nitrogen sites is not sufficient to induce DA adsorption and that the organization of the carbon scaffold induced by the annealing is the most important factor. As anC:N1 and anC:N2 show different coverages despite their similar $\mathrm{N} / \mathrm{C}$ at.\% and $\mathrm{N}_{\mathrm{G}} / \mathrm{N}_{\mathrm{P}}$ concentration, we conclude that differences in graphitic clustering, or more specifically average lateral graphitic cluster size between the two surfaces, are the origin of these variations. This suggests that DA adsorption experiments may be used as an effective probe of the interfacial carbon nanostructure that is relevant to the electroactive surface thus complementing information on defect density derived from bulk methods such as Raman spectroscopy.

\section{Conclusions}

In this work we have prepared graphitic carbon model systems with and without the presence of nitrogen heteroatoms and characterized their surface chemistry and carbon nanostructure using a combination of XPS, Raman spectroscopy, and DFT calculations. We have shown that these graphitic carbon systems exhibit adsorption of dopamine with results suggesting that the coverage of this probe is influenced both by the presence of $\mathrm{N}$-sites and by the degree of the graphitization of the carbon surface. Theoretical studies suggest that the adsorption at the surface is controlled by $\pi$-stacking interactions between graphitic clusters at the surface and the aryl moiety. 
The incorporation of nitrogen sites into the carbon scaffold may enhance adsorption, particularly at graphitic valley sites, but the data do not support the notion that DA adsorption is controlled primarily by particular $\mathrm{N}$ sites, since two model systems with identical N/C \% and nitrogen surface chemistry have highly different coverages of both molecules. It is clear that the chemical effects of $\mathrm{N}$-doping can be counteracted almost entirely by its structurally disruptive effects. Our results indicate that the effect of carbon nanostructuring and organization on the adsorption and redox response of DA should be regarded as of greater significance than the presence of specific N-functional groups. Therefore, it appears important to further explore this interplay between $\mathrm{N}$-functional groups and carbon nanostructuring in their local environment to better understand electrocatalysis at nitrogenated carbon electrodes in general.

Nitrogenated carbons have been used by the electroanalytical community in general for many years and have been used in dopamine detection in particular by many groups. We expect that other aryl systems, such as other catechols and molecules with biological relevance, may display similar behaviour. Indeed, work is currently underway in our group to explore the interactions of other aryl systems with model carbon systems. These interactions may be explored not only in the context of designing biosensors based on graphitic carbons, but also in the use of graphitic amorphous carbon model systems as platforms for the study of structural organization of disordered carbons. Finally, it is likely that the organization of the carbon scaffold has relevance to other inner-sphere redox processes such as oxygen reduction, for which heteroatom doped carbons are frequently employed. Work is currently underway in our group to understand the effects of modifying carbon nanostructure of different carbon model systems on the ORR. 


\section{AUTHOR INFORMATION \\ Corresponding Authors \\ * colavitp@tcd.ie* garciamm@tcd.ie}

\section{ACKNOWLEDGMENT}

This publication has emanated from research conducted with the financial support of Science Foundation Ireland under Grant No. 13/CDA/2213 and of the Irish Research Council under Grant No. GOIPG/2014/399. Use of the XPS of I. V. Shvets and C. McGuinness provided under SFI Equipment Infrastructure funds. We also acknowledge generous computing allocation time in the Kelvin cluster maintained by the Trinity Centre for High Performance Computing, which was funded through grants from the Higher Education Authority, through its PRTLI program.

Supporting Information Available: C 1s XPS Spectra, comparison of CV waveforms, discussion of FWHM data from voltammetry, capacitance determinations, additional figures of DFT structures and atomic coordinates of all optimized structures. This material is available free of charge via the Internet at http://pubs.acs.org.
ABBREVIATIONS
DA - Dopamine
$\mathrm{CV}$ - Cyclic Voltammetry
ORR - Oxygen Reduction Reaction
XPS - X-Ray Photoelectron Spectroscopy 
anC - Amorphous Carbon annealed at $900{ }^{\circ} \mathrm{C}$

anC:N - Nitrogenated Amorphous Carbon annealed at $900{ }^{\circ} \mathrm{C}$

\section{REFERENCES}

1. To, J. W. F.; Ng, J. W. D.; Siahrostami, S.; Koh, A. L.; Lee, Y.; Chen, Z.; Fong, K. D.; Chen, S.; He, J.; Bae, W.-G., et al., High-Performance Oxygen Reduction and Evolution Carbon Catalysis: From Mechanistic Studies to Device Integration. Nano Res. 2017, 10, 1163-1177.

2. Siahrostami, S.; Tsai, C.; Karamad, M.; Koitz, R.; García-Melchor, M.; Bajdich, M.; Vojvodic, A.; Abild-Pedersen, F.; Nørskov, J. K.; Studt, F., Two-Dimensional Materials as Catalysts for Energy Conversion. Catal. Lett. 2016, 146, 1917-1921.

3. Lin, Z.; Waller, G. H.; Liu, Y.; Liu, M.; Wong, C.-p., Simple Preparation of Nanoporous Few-Layer Nitrogen-Doped Graphene for Use as an Efficient Electrocatalyst for Oxygen Reduction and Oxygen Evolution Reactions. Carbon 2013, 53, 130-136.

4. $\quad$ Yadav, R. M.; Wu, J.; Kochandra, R.; Ma, L.; Tiwary, C. S.; Ge, L.; Ye, G.; Vajtai, R.; Lou, J.; Ajayan, P. M., Carbon Nitrogen Nanotubes as Efficient Bifunctional Electrocatalysts for Oxygen Reduction and Evolution Reactions. ACS Appl. Mater. Interfaces 2015, 7, 11991-12000.

5. Behan, J. A.; Stamatin, S. N.; Hoque, M. K.; Ciapetti, G.; Zen, F.; Esteban-Tejeda, L.; Colavita, P. E., Combined Optoelectronic and Electrochemical Study of Nitrogenated Carbon Electrodes. J. Phys. Chem. C 2017, 121, 6596-6604.

6. Chen, J.; Wang, X.; Cui, X.; Yang, G.; Zheng, W., Amorphous Carbon Enriched with Pyridinic Nitrogen as an Efficient Metal-Free Electrocatalyst for Oxygen Reduction Reaction. Chem. Commun. 2014, 50, 557-559.

7. Chen, J. Y.; Wang, X.; Cui, X. Q.; Yang, G. M.; Zheng, W. T., One-Step Synthesis of NDoped Amorphous Carbon at Relatively Low Temperature as Excellent Metal-Free Electrocatalyst for Oxygen Reduction. Catal. Commun. 2014, 46, 161-164.

8. Ajay, K.; Abhijit, G.; Pagona, P., Thermal Stability Study of Nitrogen Functionalities in a Graphene Network. J. Phys.: Condens. Matter 2012, 24, 235503.

9. Lai, L.; Potts, J. R.; Zhan, D.; Wang, L.; Poh, C. K.; Tang, C.; Gong, H.; Shen, Z.; Lin, J.; Ruoff, R. S., Exploration of the Active Center Structure of Nitrogen-Doped Graphene-Based Catalysts for Oxygen Reduction Reaction. Energy Environ. Sci. 2012, 5, 7936-7942.

10. Li, X.-F.; Lian, K.-Y.; Liu, L.; Wu, Y.; Qiu, Q.; Jiang, J.; Deng, M.; Luo, Y., Unraveling the Formation Mechanism of Graphitic Nitrogen-Doping in Thermally Treated Graphene with Ammonia. Sci. Rep. 2016, 6, 23495. 
11. Stamatin, S. N.; Hussainova, I.; Ivanov, R.; Colavita, P. E., Quantifying Graphitic Edge Exposure in Graphene-Based Materials and Its Role in Oxygen Reduction Reactions. ACS Catal. 2016, 6, 5215-5221.

12. Sharifi, T.; Hu, G.; Jia, X.; Wågberg, T., Formation of Active Sites for Oxygen Reduction Reactions by Transformation of Nitrogen Functionalities in Nitrogen-Doped Carbon Nanotubes. ACS Nano 2012, 6, 8904-8912.

13. Dai, L.; Xue, Y.; Qu, L.; Choi, H.-J.; Baek, J.-B., Metal-Free Catalysts for Oxygen Reduction Reaction. Chem. Rev. 2015, 115, 4823-4892.

14. Hu, C.; Dai, L., Carbon-Based Metal-Free Catalysts for Electrocatalysis Beyond the Orr. Angew. Chem. Int. Ed. 2016, 55, 11736-11758.

15. Kleinsorge, B.; Ferrari, A. C.; Robertson, J.; Milne, W. I.; Waidmann, S.; Hearne, S., Bonding Regimes of Nitrogen in Amorphous Carbon. Diamond Relat. Mater. 2000, 9, 643-648.

16. Guo, D.; Shibuya, R.; Akiba, C.; Saji, S.; Kondo, T.; Nakamura, J., Active Sites of Nitrogen-Doped Carbon Materials for Oxygen Reduction Reaction Clarified Using Model Catalysts. Science 2016, 351, 361-365.

17. DuVall, S. H.; McCreery, R. L., Self-Catalysis by Catechols and Quinones During Heterogeneous Electron Transfer at Carbon Electrodes. J. Am. Chem. Soc. 2000, 122, 67596764.

18. DuVall, S. H.; McCreery, R. L., Control of Catechol and Hydroquinone ElectronTransfer Kinetics on Native and Modified Glassy Carbon Electrodes. Anal. Chem. 1999, 71, 4594-4602.

19. Jacq, J., Schema Carre: Etablissement Et Discussion De L'equation Generale De La Courbe Intensite-Potentiel En Regime Stationnaire Et Diffusion Convective. J. Electroanal. Chem. Interfacial Electrochem. 1971, 29, 149-180.

20. Laviron, E., Electrochemical Reactions with Protonations at Equilibrium: Part Xii. The 2 $\mathrm{E}^{-}, 2 \mathrm{H}^{+}$Homogeneous Isotopic Electron Exchange Reaction (Nine-Member Square Scheme). $J$. Electroanal. Chem. Interfacial Electrochem. 1984, 169, 29-46.

21. Chen, L.; Li, X.; Tanner, E. E. L.; Compton, R. G., Catechol Adsorption on Graphene Nanoplatelets: Isotherm, Flat to Vertical Phase Transition and Desorption Kinetics. Chemical Science 2017, 8, 4771-4778.

22. Fernández, A. C. R.; Castellani, N. J., Noncovalent Interactions between Dopamine and Regular and Defective Graphene. ChemPhysChem 2017, 18, 2065-2080.

23. Ortiz-Medina, J.; López-Urías, F.; Terrones, H.; Rodríguez-Macías, F. J.; Endo, M.; Terrones, M., Differential Response of Doped/Defective Graphene and Dopamine to Electric Fields: A Density Functional Theory Study. J. Phys. Chem. C 2015, 119, 13972-13978. 
24. Deakin, M. R.; Kovach, P. M.; Stutts, K.; Wightman, R. M., Heterogeneous Mechanisms of the Oxidation of Catechols and Ascorbic Acid at Carbon Electrodes. Anal. Chem. 1986, 58, 1474-1480.

25. Gai, P.; Zhang, H.; Zhang, Y.; Liu, W.; Zhu, G.; Zhang, X.; Chen, J., Simultaneous Electrochemical Detection of Ascorbic Acid, Dopamine and Uric Acid Based on Nitrogen Doped Porous Carbon Nanopolyhedra. J. Mater. Chem. B 2013, 1, 2742-2749.

26. Sheng, Z.-H.; Zheng, X.-Q.; Xu, J.-Y.; Bao, W.-J.; Wang, F.-B.; Xia, X.-H., Electrochemical Sensor Based on Nitrogen Doped Graphene: Simultaneous Determination of Ascorbic Acid, Dopamine and Uric Acid. Biosens. Bioelectron. 2012, 34, 125-131.

27. Tanaka, Y.; Naragino, H.; Yoshinaga, K.; Nakahara, A.; Kondo, T.; Fujishima, A.; Honda, K., Controllable Electrochemical Activities by Oxidative Treatment toward Inner-Sphere Redox Systems at N-Doped Hydrogenated Amorphous Carbon Films. Int. J. Electrochem. 2012, $2012,369130$.

28. Medeiros, R. A.; Matos, R.; Benchikh, A.; Saidani, B.; Debiemme-Chouvy, C.; Deslouis, C.; Rocha-Filho, R. C.; Fatibello-Filho, O., Amorphous Carbon Nitride as an Alternative Electrode Material in Electroanalysis: Simultaneous Determination of Dopamine and Ascorbic Acid. Anal. Chim. Acta 2013, 797, 30-39.

29. Yang, X.; Haubold, L.; DeVivo, G.; Swain, G. M., Electroanalytical Performance of Nitrogen-Containing Tetrahedral Amorphous Carbon Thin-Film Electrodes. Anal. Chem. 2012, $84,6240-6248$.

30. Chai, J.-D.; Head-Gordon, M., Long-Range Corrected Hybrid Density Functionals with Damped Atom-Atom Dispersion Corrections. Phys. Chem. Chem. Phys. 2008, 10, 6615-6620.

31. Frisch, M. J.; Trucks, G. W.; Schlegel, H. B.; Scuseria, G. E.; Robb, M. A.; Cheeseman, J. R.; Scalmani, G.; Barone, V.; Mennucci, B.; Petersson, G. A., et al., Gaussian 09, Revision E.01. Gaussian Inc., Wallingford CT, 2009.

32. Penas-Defrutos, M. N.; Bartolome, C.; Garcia-Melchor, M.; Espinet, P., Hidden ArylExchange Processes in Stable 16e Rhiii [Rhcp*Ar2] Complexes, and Their Unexpected Transmetalation Mechanism. Chem. Commun. 2018, 54, 984-987.

33. Titantah, J. T.; Lamoen, D., Carbon and Nitrogen 1s Energy Levels in Amorphous Carbon Nitride Systems: Xps Interpretation Using First-Principles. Diamond Relat. Mater. 2007, $16,581-588$.

34. Qu, L.; Liu, Y.; Baek, J.-B.; Dai, L., Nitrogen-Doped Graphene as Efficient Metal-Free Electrocatalyst for Oxygen Reduction in Fuel Cells. ACS Nano 2010, 4, 1321-1326.

35. Le Normand, F.; Hommet, J.; Szörényi, T.; Fuchs, C.; Fogarassy, E., Xps Study of Pulsed Laser Deposited Cn ${ }_{\mathrm{x}}$ Films. Phys. Rev. B 2001, 64, 235416. 
36. Díaz, J.; Paolicelli, G.; Ferrer, S.; Comin, F., Separation of the $\mathrm{Sp}^{3}$ and $\mathrm{Sp}^{2}$ Components in the C 1s Photoemission Spectra of Amorphous Carbon Films. Phys. Rev. B 1996, 54, 80648069.

37. Ferrari, A. C.; Rodil, S. E.; Robertson, J., Interpretation of Infrared and Raman Spectra of Amorphous Carbon Nitrides. Phys. Rev. B 2003, 67, 155306.

38. Perini, L.; Durante, C.; Favaro, M.; Perazzolo, V.; Agnoli, S.; Schneider, O.; Granozzi, G.; Gennaro, A., Metal-Support Interaction in Platinum and Palladium Nanoparticles Loaded on Nitrogen-Doped Mesoporous Carbon for Oxygen Reduction Reaction. ACS Appl. Mater. Interfaces 2015, 7, 1170-1179.

39. Ferrari, A. C.; Robertson, J., Interpretation of Raman Spectra of Disordered and Amorphous Carbon. Phys. Rev. B 2000, 61, 14095-14107.

40. Waidmann, S.; Knupfer, M.; Fink, J.; Kleinsorge, B.; Robertson, J., Electronic Structure Studies of Undoped and Nitrogen-Doped Tetrahedral Amorphous Carbon Using HighResolution Electron Energy-Loss Spectroscopy. J. Appl. Phys. 2001, 89, 3783-3792.

41. Laidani, N.; Guzman, L.; Miotello, A.; Brusa, R. S.; Karwasz, G. P.; Zecca, A.; Bottani, C.; Perrière, J., Nitrogen Effects on the Microstructural Evolution of Carbon Films under Thermal Annealing. Nucl. Instrum. Methods Phys. Res., Sect. B 1997, 122, 553-558.

42. Ferrari, A. C.; Robertson, J., Resonant Raman Spectroscopy of Disordered, Amorphous, and Diamondlike Carbon. Phys. Rev. B 2001, 64, 075414.

43. Murphy, D. M.; Cullen, R. J.; Jayasundara, D. R.; Doyle, R. L.; Lyons, M. E. G.; Colavita, P. E., Heterogeneous Charge Transfer at the Amorphous Carbon/Solution Interface: Effect on the Spontaneous Attachment of Aryldiazonium Salts. J. Phys. Chem. C 2013, 117, $22768-22777$.

44. McCreery, R. L., Advanced Carbon Electrode Materials for Molecular Electrochemistry. Chem. Rev. 2008, 108, 2646-87.

45. Downard, A. J.; Roddick, A. D.; Bond, A. M., Covalent Modification of Carbon Electrodes for Voltammetric Differentiation of Dopamine and Ascorbic Acid. Anal. Chim. Acta 1995, 317, 303-310.

46. Corona-Avendaño, S.; Alarcón-Angeles, G.; Ramírez-Silva, M. T.; Rosquete-Pina, G.; Romero-Romo, M.; Palomar-Pardavé, M., On the Electrochemistry of Dopamine in Aqueous Solution. Part I: The Role of [Sds] on the Voltammetric Behavior of Dopamine on a Carbon Paste Electrode. J. Electroanal. Chem. 2007, 609, 17-26.

47. Patel, A. N.; Tan, S.-y.; Miller, T. S.; Macpherson, J. V.; Unwin, P. R., Comparison and Reappraisal of Carbon Electrodes for the Voltammetric Detection of Dopamine. Anal. Chem. 2013, 85, 11755-11764. 
48. Laviron, E., Electrochemical Reactions with Protonations at Equilibrium: Part X. The Kinetics of the P-Benzoquinone/Hydroquinone Couple on a Platinum Electrode. J. Electroanal. Chem. Interfacial Electrochem. 1984, 164, 213-227.

49. Nicholson, R. S., Theory and Application of Cyclic Voltammetry for Measurement of Electrode Reaction Kinetics. Anal. Chem. 1965, 37, 1351-1355.

50. $\quad$ Compton, R. G.; Banks, C. E., Understanding Voltammetry. 2nd ed.; Imperial College Press: London, 2011.

51. Wopschall, R. H.; Shain, I., Effects of Adsorption of Electroactive Species in Stationary Electrode Polarography. Anal. Chem. 1967, 39, 1514-1527.

52. Nicholson, R. S.; Shain, I., Theory of Stationary Electrode Polarography. Single Scan and Cyclic Methods Applied to Reversible, Irreversible, and Kinetic Systems. Anal. Chem. 1964, 36, 706-723.

53. Laviron, E., Adsorption, Autoinhibition and Autocatalysis in Polarography and in Linear Potential Sweep Voltammetry. J. Electroanal. Chem. Interfacial Electrochem. 1974, 52, 355393.

54. Angerstein-Kozlowska, H.; Klinger, J.; Conway, B. E., Computer Simulation of the Kinetic Behaviour of Surface Reactions Driven by a Linear Potential Sweep: Part I. Model 1Electron Reaction with a Single Adsorbed Species. J. Electroanal. Chem. Interfacial Electrochem. 1977, 75, 45-60. 


\section{TOC Graphic}

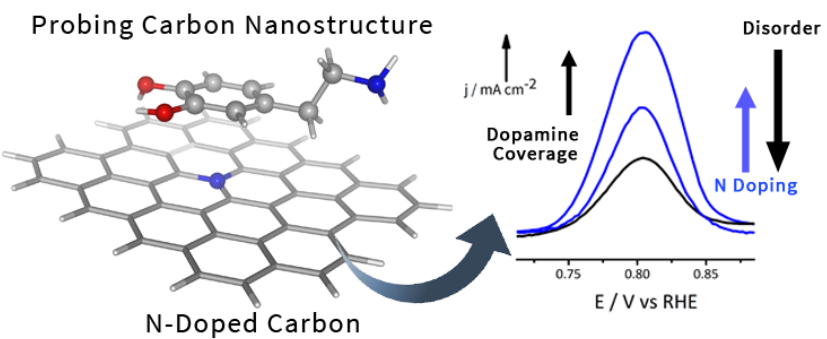

